\title{
Survey of Manufacturing Company Expectations Based on the SME Four Pillars of Manufacturing Knowledge
}

\section{Prof. Paul Nutter, Ohio Northern University}

Paul Nutter, CMfgE, CQE, CQA, is an Associate Professor in the Department of Technological Studies at Ohio Northern University. He has been teaching manufacturing technology since 2000, and has 26 years of experience in industrial and manufacturing engineering, primarily with Rockwell Automotive. Nutter is active in the Society of Manufacturing Engineers as faculty advisor for SME Student Chapter S186, and was the 2011 chair of the SME Technical Community Steering Committee. He previously served as chair of the 2009 \& 2010 Automated Manufacturing and Assembly Community, the 2007 \& 2008 Simulation Technical Group, on the 2006 Member Council, the 2005 Student Relations Subcommittee, and the 2005 SME Youth Program Task Force. He has also participated on various committees for annual conferences, and received the 2009 national SME Award of Merit.

\section{Prof. Robert L. Mott P.E., University of Dayton}

Robert L. Mott, P.E. is professor emeritus of engineering technology at the University of Dayton. He serves the Society of Manufacturing Engineers through the Manufacturing Education \& Research Community and the SME Center for Education and he is a recipient of the SME Education Award. He has authored four textbooks. Applied Fluid Mechanics 6th ed, Applied Strength of Materials 5th ed, Statics and Strength of Materials, 1st ed, and Machine Elements in Mechanical Design 5rd ed, all published by Pearson/Prentice-Hall. He also works with the NSF-sponsored National Center for Manufacturing Education at Sinclair Community College in Dayton, Ohio. He is a Fellow of the American Society for Engineering Education (ASEE) and the recipient of the James H. McGraw Award, the Frederick J. Berger Award, and the Archie Higdon Distinguished Mechanics Educator Award from ASEE. He is also a member of ASME. His degrees are the BSME from General Motors Institute (now Kettering University) and the M.S.M.E. from Purdue University.

\section{Mr. Carl R Williams, University of Memphis}

Associate professor and Coordinator for Graduate Studies for the Department of Engineering Technology. B.S. in business and B.S. in engineering from Mississippi State; M.B.A. in marketing and M.S. in Industrial Systems Engineering from the University of Memphis and Ph.D.-ABD in supply chain. P.E. by exam in Manufacturing Engineering, Certified Manufacturing Engineer, certified Associate in Engineering Management. Most active with SME, including Faculty Adviser to SME student chapter, Membership Consultant for area chapters, extensive work with professional licensure and accreditation. Recipient of the SME Joseph A Siegel Award.

\section{Mark J. Stratton, Society of Manufacturing Engineers}

Society of Manufacturing Engineers, Education Relations Manager, Dearborn, Mich. 


\title{
Survey of Manufacturing Company Expectations Based on the SME Four Pillars of Manufacturing Knowledge
}

\begin{abstract}
Survey results are presented that identify and compare industry and academic perspectives of topics in a curriculum model based on the Four Pillars of Manufacturing Knowledge that a incorporates topics from the Society of Manufacturing Engineers Body of Knowledge for Certification of Manufacturing Engineering and Technologists with accreditation criteria. The model divides the broad field of Manufacturing Engineering into teachable divisions aligned to industry needs. The survey results indicate there is a good match between the model and expectations. In addition, the survey identifies higher priority manufacturing topics for education, and provides insights into how different types of academic programs prioritize the various topics of manufacturing.
\end{abstract}

\section{Introduction}

Manufacturing in the United States is increasingly being recognized for its importance. Federal policies, strategies, and funding are increasing for manufacturing education and training, research, and innovation centers to expedite the movement of lab concepts to production practices. It comes at a time when industry is experiencing shortages of talent to meet current demand, and faces eminent retirement of many of its technical and engineering workforce that will fuel future demand. In the SME "Workforce Imperative: A Manufacturing Education Strategy" white paper, recommendations are made to ensure preparation of existing and future workforce. These include working together to attract students into manufacturing, articulate a standard core of manufacturing knowledge, improve manufacturing curriculum, integrate manufacturing into STEM education, develop faculty, and strategically deploy resources.

This paper describes the results of an online survey that was distributed to a broad audience including managers, company owners, engineers, educators and education administrators. The objective of the survey was to evaluate the relative importance of a common core of manufacturing topics identified in the SME Four Pillars of Manufacturing Knowledge (SME, 2012) which includes the topics from the Society of Manufacturing Engineers Body of Knowledge for Certification of Manufacturing Engineering and Technologists and ABET program criteria. Respondents indicated (in their opinion) how well graduates should be prepared in each topic. A secondary benefit of this survey and evaluation is the validation of the topics and structure of the Four Pillars of Manufacturing Knowledge, with the opportunity to contribute to evolutionary improvements.

This paper provides documentation and analysis of manufacturing company priorities for manufacturing topics in engineering or technology programs. Academic programs can benefit by assessing their effectiveness to fulfill the needs and expectations of manufacturing industries, gaining insights for appropriate curriculum revisions to enhance the job-readiness of students to serve these ‘customers' of our academic services. 
The paper ends with a summary of observations, conclusions, and recommendations for use of the results. Among others, some significant outcomes are:

1. The Four Pillars of Manufacturing Knowledge model is a useful tool for informing a wide set of populations, both industry professionals and educators, about the breadth of the manufacturing field.

2. By identifying respondents with their focus among six different types of academic programs, the survey responses provide insights on the differences in relative importance of the large number of topics that make up the manufacturing field.

3. The survey results show that there are meaningful differences among the variety of types of manufacturing programs and that the Four Pillars model is useful in curriculum planning. While not being prescriptive, the model can help educators tailor their programs to meet the needs of the industries served and the career expectations of their graduates.

\section{The Four Pillars of Manufacturing Knowledge}

Foundational for this survey was definition of the various topics that compose the fields of manufacturing. The Society of Manufacturing Engineers (SME) developed the term "Four Pillars of Manufacturing Knowledge", influenced by the conversations conducted by the Manufacturing Education \& Research community. The SME Center for Education identified a clear need for a common model of the manufacturing engineering field that could aid in planning the continuous improvement of manufacturing-related curricula of all types, and to help the broader society better understand the wide breadth and deep depth of the field. To this end, the center leaders created the Four Pillars of Manufacturing Knowledge in early 2011. See Figure 1.

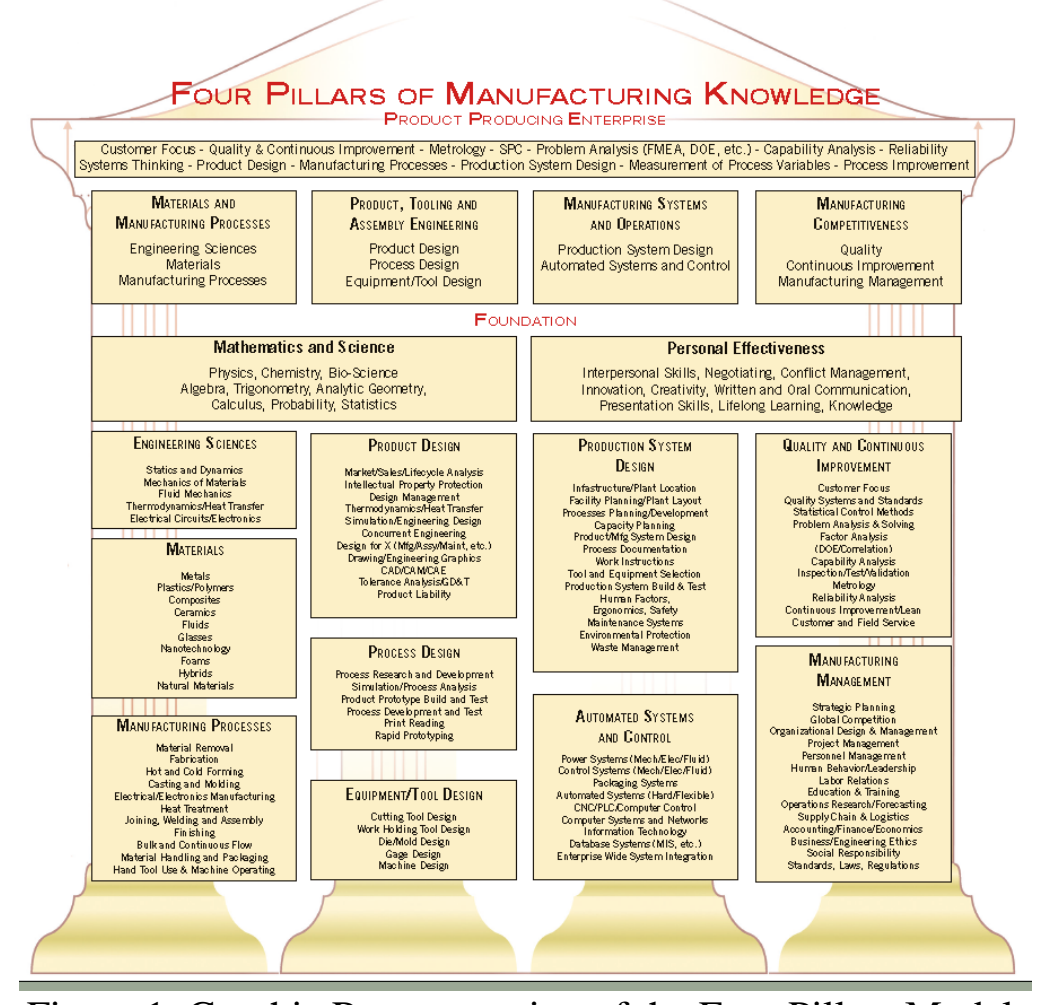

Figure 1. Graphic Representation of the Four Pillars Model. For a PDF and details of the above go to www.sme.org/fourpillars 
The Four Pillars model graphically depicts the topics from the SME document, Certified Manufacturing Technologist and Certified Manufacturing Engineer - Body of Knowledge, (SME, 2010) organized under the four categories of program criteria for ABET accreditation of Manufacturing Engineering and Manufacturing Engineering Technology programs (ABET, 2012). These topics were rigorously developed with significant industry input on the skills and knowledge required by manufacturing professionals. First introduced at the June 2011 SME Annual Conference, the model was also a major component of the research on manufacturing educational needs entitled "Curricula 2015: A Four Year Strategic Plan for Manufacturing Education.” (SME, 2011). The headings in the upper four boxes in Figure 1 identify the Four Pillars.

This model essentially differentiates the unique character of manufacturing, manufacturing engineering, and manufacturing engineering technology, defines the standard for advanced manufacturing topics, and provides a body of knowledge with which all those engaged in advanced manufacturing education can align. It is a tool for promoting greater understanding of the breadth and depth of the field of manufacturing engineering. Initiatives are ongoing, led by the SME Center for Education, to build on this foundation, to promulgate the model broadly within SME, and to engage in dialog with other professional societies that represent engineering, engineering technology, industrial technology, and related educational programs from whose graduates enter manufacturing-related career paths.

A variety of academic programs engage in manufacturing instruction with each having its own emphases, typically targeted to employment in certain segments of manufacturing fields. Examples of those programs that include the term manufacturing are Manufacturing Engineering, Manufacturing Engineering Technology, and Industrial TechnologyManufacturing. In addition, some programs are baccalaureate level and some are associate level.

One objective of this survey was to provide input to the decision making by manufacturing educators in these types of programs for manufacturing education. What content and relative emphasis should be placed on the many topics that make up the field of manufacturing?

\section{Survey Instrument}

The survey was created in Survey Monkey, and then distributed as an email to a significant number of industry practitioners and educators through SME and ASEE distribution and list serves. An incentive of $\$ 100$ was offered in a drawing of respondents who completed the survey.

1. Responders were asked for which kinds of academic programs they are primarily responding. Multiple responses were permitted. Six options were provided:

- Bachelor Degree in Engineering (BS-Engr.)

- Associate Degree in Engineering Technology (ASET)

- Bachelor Degree in Engineering Technology (BSET)

- Associate Degree in Industrial Technology (ASIT)

- Bachelor Degree in Industrial Technology — Management Track (BSIT-Mgt)

- Bachelor Degree in Industrial Technology — Technical Track (BSIT-Tech) 
2. Survey responders were asked to identify their primary background: Manufacturing management (Industry), Manufacturing engineering (Industry), Manufacturing education (Academia), or Professional or Academic administration. Multiple responses were permitted for those whose careers spanned more than one area to a significant degree.

3. Eleven sets of topics, derived primarily from the Four Pillars model, were then presented and the responders were asked to indicate how well prepared graduates should be on each topic on a five-point Likert scale. The selection options were:

$\begin{array}{cllll}\begin{array}{l}\text { Not Important } \\ \text { (Not used } \\ \text { or N/A) }\end{array} & \begin{array}{l}\text { Useful } \\ \text { (Remember) }\end{array} & \begin{array}{c}\text { Important } \\ \text { (Understand } \\ \text { or Apply) }\end{array} & \begin{array}{l}\text { Very Important } \\ \text { (Analyze } \\ \text { or Evaluate) }\end{array} & \begin{array}{l}\text { Critical } \\ \text { (Create) }\end{array}\end{array}$

The terms in parentheses were derived from concepts such as the Bloom's Taxonomy to gauge the level at which learners should demonstrate proficiency. During analysis of the data, values of zero to four $(0,1,2,3,4)$ were used for the five response options. Therefore, the higher numbers indicate higher expectations of proficiency.

The ten major subject areas shown on the Four Pillars model made up the first ten sets of topics in the survey with each having multiple sub-topics ranging from five to twelve. The 11th area was labeled "Miscellaneous topics" and it included five items that were not specifically mentioned in the Four Pillar model. A total of 99 topics were included in the eleven sets.

4. The final survey item asked each responder to indicate their primary fields of manufacturing experiences, with 20 options provided.

Appendix A. lists the sorted Overall Rankings by Survey Respondents

Appendix B. provides Number and Distribution of Respondents, with Demographics

Appendix C. gives Comments by Survey Respondents to Indicated Questions in the Survey

\section{Analysis of data}

A number of subgroups were established for comparison on the 99 topic areas. Positions were also regrouped for comparison of industry verses academics. These groupings include:

- Six Degree programs:

- BS-Engr. (BS Degree-Engineering)

- ASET (Associate Degree-Engineering Technology)

- BSET (BS Degree-Engineering Technology)

- ASIT (Associate Degree-Industrial Technology)

— BSIT-Mgt (BS Degree-Industrial Technology — Management Track)

— BSIT-Tech (BS Degree-Industrial Technology — Technical Track)

- Twenty industry areas of practice. 
- Four professional positions:

— Manufacturing Management (industry practitioners )

- Manufacturing Engineering (industry practitioners)

- Manufacturing Education (academia)

- Academic Administration

One of the more interesting comparisons was the differences in ranking and importance between the positions, and particularly Academic Administrators seemed to have a considerably different opinion than the other groups on numerous topics. Many of these were statistically significant differences.

To help correlate the discussion of results with the graphic representation of the Four Pillars model in Figure 1, please note there are ten categories of topics aligned under the four pillars.

1. Pillar 1: Materials and Manufacturing Processes - Three categories

a. Engineering Sciences

b. Materials

c. Manufacturing Processes

2. Pillar 2: Product, Tooling, and Assembly Engineering - Three categories

a. Product Design

b. Process Design

c. Equipment/Tool Design

3. Pillar 3: Manufacturing Systems and Operations - Two categories

a. Production System Design

b. Automated Systems and Control

4. Pillar 4: Manufacturing Competitiveness - Two categories

a. Quality and Continuous Improvement

b. Manufacturing Management

The following pages display box-and-whisker diagrams of the data. These graphically show max., min., and ranges for each of the ten categories of topics aligned under the four pillars (the boxes in the Four Pillars Model) for each of the degree programs. There were some natural topic area clustering and the patterns for the Industrial Technology (IT) programs seemed to have similar patterns with large clusters, while there was more distinction between the clusters for the Engineering Technology programs and for BS-Engineering as well. It is interesting to note that the topic groupings actually have a clustering effect that is not the same between the various degree programs.

The following Box-and-whisker diagrams presented in this research are not the traditional quartile style. While the vertical whiskers indicate the range of responses low and high ratings and the box is centered about the sample mean, box height has a different basis. The height of the box is the z-score 80 percentile range which is a function of sample standard deviation and sample size and is intended to provide insight into significant differences. This allows one-tailed comparison at $10 \%$ in either direction. The actual tests are $90 \%$ with $10 \%$ error. 
BS Degree-Engineering

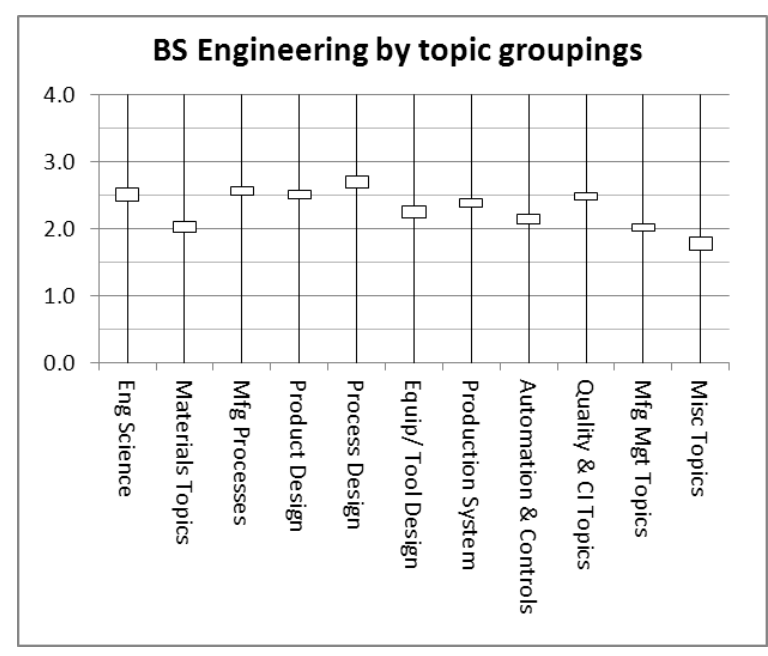

For BS-Engineering, “Process Design” clearly stands out as significantly $(p=2.2 \%)$ the highest priority of topic groupings.

The remaining topic groupings are significantly different from all other topic groupings except for one pair that are clustered. "Manufacturing Management” and “Materials” are not significantly different $(p=42.9 \%)$

Another observation is that due to large standard deviations, "Quality \& CI (continuous improvement) Topics” are not significantly different from "Product Design" and

"Engineering Science" topic groupings when comparing the larger mean and standard deviation to the smaller mean. However, when comparing the smaller mean and standard deviation of the "Quality \& CI" to the other two larger mean topic group distributions there is a statistical significance ( $\mathrm{p}=3.2 \% \& 4.7 \%$ respectively).

BS-Engineering showed a central clustering of three topic group areas: "Production System," “Equip/Tool Design”, and “Automation \& Controls” appear to provide a block of topic groups that are quite independent and most statistically significantly different from all other groups. It is quite interesting that "Materials Topics" and "Manufacturing Management Topics" are in a statistical tie ( $\mathrm{p}=42.9 \%)$ for the lowest of the original 10 topic areas, and "Misc. Topics" were clearly and significantly the lowest, alone at $11^{\text {th }}$ (largest p-value comparison of means is $0.3 \%$ ). As will be explained later, that $11^{\text {th }}$ non-model category is significantly different for all except the two BSIT programs. This lowest rank topic group may provide insight for the BSIT programs.

\section{Associate Degree-Engineering Technology}

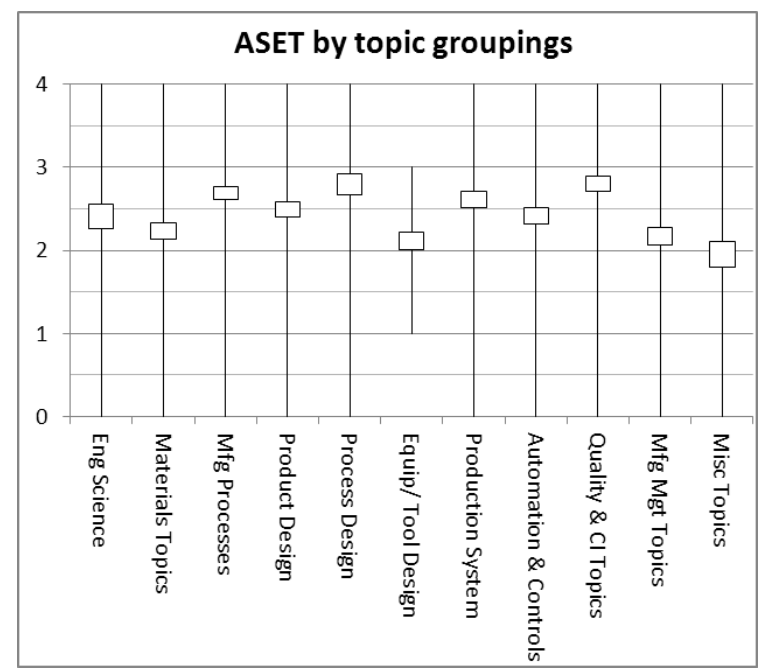

As with most degree programs, topic groupings had a clustering effect in pairs or sets of three or even more. For ASET, "Process Design" is highest, but it is not significantly different from “Quality \& CI)” ( $\mathrm{p}=48.2 \%)$. "Mfg Processes” is significantly different from "Quality and CI” ( $\mathrm{p}=$ $5.7 \%$ ), but not significantly different from "Process Design" ( $p=13.0 \%)$

Similarly, there is no significant difference between "Manufacturing Processes" and "Product System Design” ( $p=12.9 \%)$

Thus this first cluster of topic groupings is a significantly different grouping from all other topic groups and clusters. 
The second cluster has three topic groups: "Product Design", "Eng Sciences" \& “Automation \& Controls" as being not statistically different (p-values range from $12.8 \%$ to exactly equal at $50 \%)$.

The third grouping is "Materials," "Mfg Management Topics," \& "Equip/Tool Design," in that order. Materials and Equipment/Tool Design are significantly different ( $(\mathrm{p}=6.5 \%)$ but Manufacturing Management, the middle of these three topic groups is not significantly different from the other two (p-values all in the low $20 \%$ range)

The "Misc. Topics" were the lowest for all degree programs, and were significantly the lowest for four of the degree programs BS-Eng, ASET, BSET \& ASIT.

\section{BS Degree-Engineering Technology}

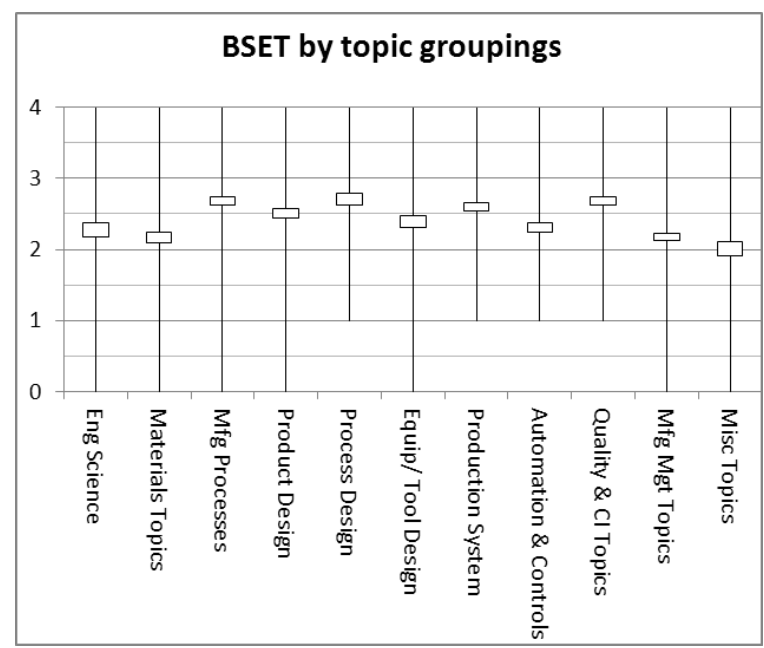

This provided a slightly different order from the previous two degree programs, as well as other degree programs. Notice that the box and whisker chart shows no zeros for four topic areas, even though some were not among the highest ranked topic groups. The absence of a zero score indicates that not even one respondent indicated that any of the topics in these groups was unimportant or not applicable.

There is the same initial cluster, with slightly different order as the ASET degree program but the same initial grouping. This turns out to have three basic topic grouping clusters with no significant differences within the cluster, but significant differences between clusters. Three topic groups were significantly different from all others: "Production System Design” (largest pvalue was 3.7\%), "Product Design" (largest p-value with any other group was 2.9\%) and "Equipment/Tool Design" (significantly different at the 9.8\% level with "Automation and Controls”).

The second clustering of topic groups was "Automation and Controls" with "Engineering Sciences" (p- value at 30.9\%), but there was a tie between this second and the third cluster. The difference in "Engineering Sciences" and "Manufacturing Management" was not significant ( $\mathrm{p}=$ $11.3 \%$ ) when evaluating the mean of "Manufacturing Management" to the distribution of "Engineering Science". However, when comparing in the opposite direction, the mean of "Engineering Science" to the distribution of "Manufacturing Management" topic grouping there is significant difference $(\mathrm{p}=1.3 \%)$. 
Associate Degree-Industrial Technology

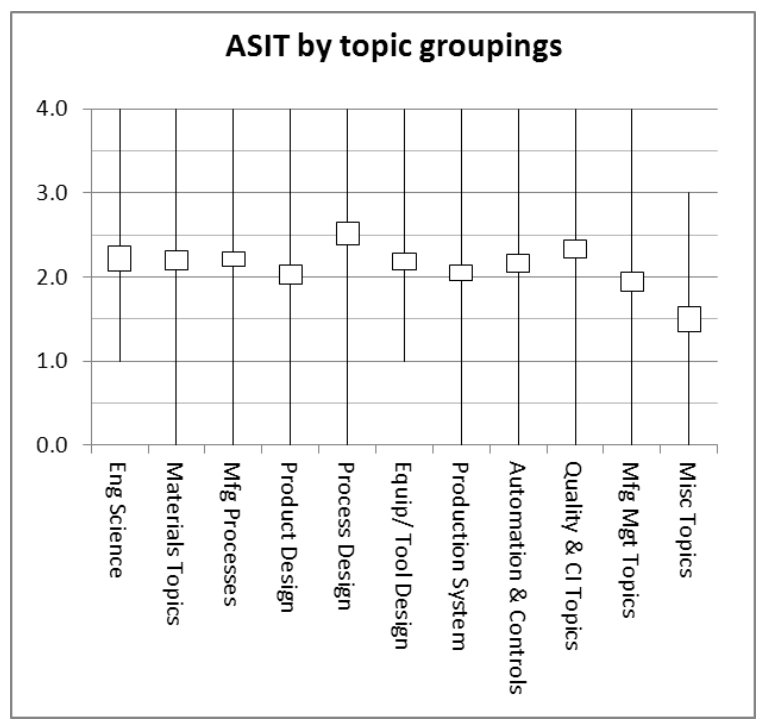

ASIT has less significance between the clusters, and larger number of groups in a central cluster.

This is the only degree program where for the "Misc. Topics" there were no ratings of " 4 (critical)”, indicating any of the individual topic areas in this group are critical. This is not the case for any other degree program and the rating for this non-model group, Miscellaneous Topics" in the two BSIT degree program types has this topic group in a statistical tie with other topic groups that were in the Four Pillars Model.

The highest rated is the "Process design" topic grouping. This is significantly different from "Quality and CI" (p -= 7.5\%).

One large cluster of topic groups include those ranked third to seventh in expected proficiency. These include topic groups, in rank order: Equipment/Tool Design, Manufacturing Processes, Materials topics, Engineering Science and Automation and Controls. There is no significant difference in this large central grouping of topic areas (p-values ranged from $22.0 \%$ to 49.4\%). The eighth topic group, Production System design, is not significantly different from two of the five in that second cluster, Engineering Science and Automation \& Controls ( $p=14.2$ and 13.2 respectively), and also is not significantly different from the Product Design topic grouping which follows ( $\mathrm{p}=19.9 \%)$.

While the tenth topic, Manufacturing Management topic group is significantly different ( $\mathrm{p}=$ 4.2\%) than Production System Design topic group, it is not significantly different from Product Design $(\mathrm{p}=22.3 \%)$.

As with all previous topic groupings, the eleventh topic category, Miscellaneous Topics, was significantly different $(\mathrm{p}=0.1 \%)$ from the next closest average.

\section{$\underline{\text { BS Degree-Industrial Technology - Management Track }}$}

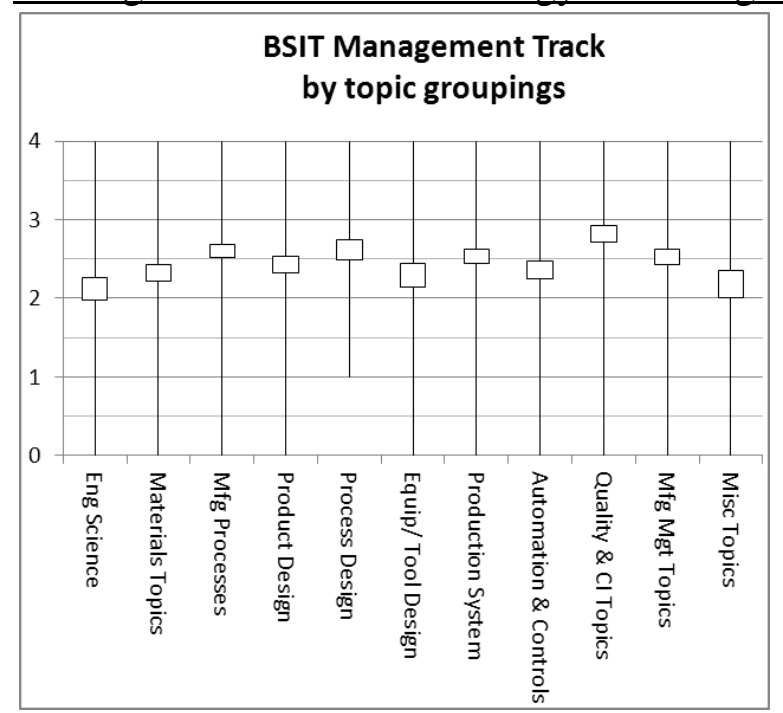

Clearly, the highest rated topic group, Quality and Continuous Improvement is significantly different from all other topic groups (the maximum p-value is $2.6 \%$ with Process Design).

A cluster of topic groups follow that include the second to the fifth. These include, in rank order: Process Design, Manufacturing Processes, Production System Design, and Manufacturing Management. There is one p-value of $9.6 \%$ between Manufacturing Management and Manufacturing Processes when tested in that order. However, when testing in the opposite 
direction, the mean of the latter with the distribution of the former the p-value is $13.5 \%$. For this reason, the difference in proficiency rating averages for these two topic groups are considered to not be statistically significant.

While there appear to be two major but linked clusters of similarly rated topic groups, the division is not as clearly delineated as other degree programs. Perhaps this two-year degree program results represent an increased diversity of offerings and thus expectations as they seek to satisfy their respective but differing constituents.

The second large cluster includes Product Design, Automation \& Controls, Materials Topics and Equipment/Tool Design. The only significance was just over a p-value of $5.0 \%$ between the Equipment/Tool Design topic group average when compared to the Product design distribution. The opposite comparison where the latter average was compared with the former topic group distribution, however, indicated a p-value of $12.6 \%$. Thus, this is not considered to be a significant difference.

The last two topic groups included Miscellaneous Topics and Engineering Science. There was no significant difference in the ratings for these two. Interestingly the two BSIT degree programs were the only ones where the Miscellaneous Topics grouping was not significantly different from all other topic groupings.

\section{$\underline{\text { BS Degree-Industrial Technology — Technical Track }}$}

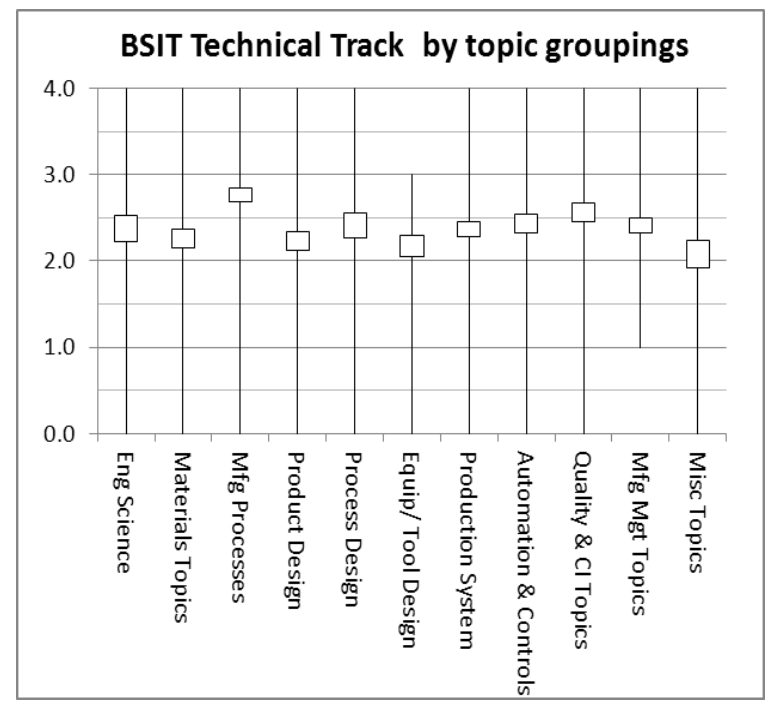

For this degree program, the first two topic groupings were significantly different as well as statistically different from all other topic groupings. "Mfg Processes” topic group was clearly the highest rated with "Quality \& Continuous Improvement” a distant second.

The remaining topic groups had two basic clusters where differences were not statistically significant. The first cluster includes, in rank order, "Mfg Mgt”, “Automation \& Controls”, "Production System Design”, "Process Design” and "Engr Science”. Average proficiency ratings for these topic groups were between 2.40 and 2.45 and there is no statistically significant difference between these.

A less defined and separated cluster of topic areas includes "Materials Topics", "Product Design", and "Equipment/Tool Design”. The first of these, "Materials", is not significantly different from "Process Design" and "Engineering Science" from the previous cluster $(\mathrm{p}=13.1 \%$ and $14.7 \%$ respectively). Also the lowest rated of the topic groups from the Four Pillars Model, "Equipment/Tool Design" is not significantly different from the "Miscellaneous Topics" group that was added for this study $(\mathrm{p}=24.1)$. "Miscellaneous" topic grouping was also not clearly 
different from "Product Design". As before, there are actually two comparisons that are made. A comparison in rank order provides a p-value of $7.6 \%$, but in the opposite direction, the p-value is $15.2 \%$. "Miscellaneous Topics” is significantly different from "Materials Topics” ( $p=2.1 \%)$.

Thus, the two BSIT degree programs are the only ones where the "Misc Topics" group was not significantly different from all other topic areas represented in the Four Pillars Model.

\section{Additional observations}

1. The five-point Likert scale (zero to four) used in the survey was effective in giving respondents opportunities to rate the relative importance of each of the 99 manufacturingrelated topics over the range: Not Important (0), Useful (1), Important (2), Very Important (3), and Critical (4).

2. The provision of additional modifiers for each rating level was helpful to relate the ratings to how professionals in the manufacturing workforce from production operators, to technicians, supervisors, engineers, and managers are expected to master each given topic. The modifiers were: (0) - Not used or N/A; (1) - Remember; (2) - UnderstandApply; (3) - Analyze-Evaluate; (4) - Create.

3. The survey results permitted the comparison of responses from several types of professionals from academia, manufacturing management, manufacturing engineering, professional administration, and academic administration.

4. The nature of the survey, its results, and the methodology used to prepare and implement the survey should have broader utility for curriculum planning as an aid to mapping the most desirable elements from among the wide array of topics listed (99) to the mission and objectives of a given type and level of program. Examples include:

a. Graduates from manufacturing-named associate degree programs should acquire a basic level of knowledge and understanding about the entire breadth of topics that make up the manufacturing engineering field. They should gain more in-depth knowledge and ability to apply materials and manufacturing processes topics, equipment/tool design topics, and quality control topics; and a solid foundation in mathematics, science, communication and other personal effectiveness skills in order to pursue higher degrees and to engage in continuing education on the job.

b. Graduates from manufacturing-named bachelor level programs would be expected to have mastered a larger number of topics from the Four Pillars of Manufacturing Knowledge to a greater depth than those from associate degree programs

c. Graduates from bachelor level management-focused industrial technology programs would be expected to place more emphasis on manufacturing processes, process design, quality, continuous improvement, production system operation, and manufacturing management and less emphasis on engineering sciences, materials, product design, equipment/tool design, and automated systems and control.

d. Graduates from non-manufacturing named programs, who enter manufacturingrelated functions of product-producing industries, should have a basic level of knowledge and understanding about the entire breadth of topics that make up the manufacturing engineering field. This will enable them to consider more carefully manufacturability within the product design process, and to participate more effectively on product development teams with other manufacturing professionals. 
Extensive statistical analysis was conducted in preparing this paper. Data and details are available to members of SME at the http://i.sme.org/myprofile/profile/ site in the SME library for the Manufacturing Education and Research Community. Information may also be requested by contacting Asst. Professor Carl Williams RE., CMfgE, at crwillia@memphis.edu .

\section{Conclusions and recommendations for use of results}

The analysis of survey results has provided insights as to how different types of educational programs can enhance their curricula with regard to manufacturing topics. Respondents included academic professionals from the viewpoints of many kinds of academic programs; engineering, engineering technology, and industrial technology at the bachelor and associate degree levels.

Globally, manufacturing is a common interest. An increasingly important aspect of engineering and technology education is preparation of a technical and engineering workforce capable of working to design and manufacture products on a global basis, for a global market place.

This paper and the model developed using the topics and methodology to test for conclusions are expected to lead to future investigations of the depth of learning on manufacturing topics that education programs should provide. Institutions with degrees, options, minors, and coursework in manufacturing should strive for an understanding of the priorities and preferences of manufacturing knowledge, skills and abilities that will benefit their customers. It should also serve as a model to understand better the extent that concepts about manufacturing and how things are made should be integrated into STEM education programs at all ages and grades.

The SME Body of Knowledge for Certification of Manufacturing Engineers and Technologist topics included in the Four Pillars of Manufacturing Knowledge provides a basis for a common understanding of manufacturing. These topics provide a basis for defining competencies and identifying levels of understanding that students should gain from various education programs.

Valuable insights are gained from this survey data and analysis. The Four Pillars model is validated to the satisfaction of the authors, and the priorities of the sample population are better understood. More significantly, there has been identification of opportunities for refinement and processing of a more extensive and more effectively designed survey to a larger population.

\section{BIBLIOGRAPHY}

ABET. (2012). Criteria for Accrediting Manufacturing Engineering and Similarly Named Programs. Retrieved from ABET: www.abet.org

SME. (2010). Certified Manufacturing Technologist and Certified Manufacturing Engineer - Body of Knowledge. Retrieved from Society of Manufacturing Engineers: http://www.sme.org/uploadedFiles/Professional_Development/Certification_and_Assessment_Solutions/tech nicalBOK.pdf

SME. (2011). Curricula 2015: A Four Year Strategic Plan for Manufacturing Education. Retrieved from Society of Manufacturing Engineers: www.C2015.com

SME. (2012). Four Pillars of Manufacturing Knowledge. Retrieved from Society of Manufacturing Engineers: www.sme.org/fourpillars 


\section{Appendix A. Overall Rankings by Survey Respondents}

A primary objective of this survey was to identify the topics of highest value to manufacturing companies, and also those of significantly lower value. Although it is understood that various institutions and industries will have different priorities, this does offer the opportunity to consider which ones might be appropriate for emphasis. At the same time, those considered less important might be reviewed to see if they represent a disproportionate component of an existing curriculum. If some topics were to be added or expanded, others would probably need to be reduced.

The following table shows the rank-order of the aggregated values for all 107 valid respondents.

Topics in overall rank order

Scoring Rubric:

$0=$ Not important (or N/A)

$1=$ Useful (Remember)

2 = Important (Understand/Apply)

$3=$ Very important (Analyze/Evaluate)

$4=$ Critical (Create)

\begin{tabular}{|l|l|l|l|l|}
\hline Rank & Topic & Mean & $\begin{array}{l}\text { Std. } \\
\text { Dev. }\end{array}$ & $\begin{array}{l}\text { Count } \\
(\mathrm{n})\end{array}$ \\
\hline 1 & Problem Analysis and Solving & 3.061 & 0.8226 & 98 \\
\hline 2 & Fabrication & 2.981 & 0.8084 & 105 \\
\hline 3 & Print Reading & 2.970 & 0.9198 & 99 \\
\hline 4 & Metals & 2.952 & 0.7768 & 105 \\
\hline 5 & Drawing/Engineering Graphics & 2.913 & 0.8978 & 103 \\
\hline 6 & CAD/CAM/CAE & 2.904 & 0.8648 & 104 \\
\hline 7 & Continuous Improvement/ Lean & 2.848 & 0.9188 & 99 \\
\hline 8 & Material Removal & 2.838 & 0.8893 & 105 \\
\hline 9 & Tolerance Analysis/GD\&T & 2.825 & 0.8451 & 103 \\
\hline 10 & Project Management & 2.813 & 0.7856 & 96 \\
\hline 11 & Product Prototype Build and Test & 2.800 & 0.8876 & 100 \\
\hline 12 & Plastics/ Polymers & 2.760 & 0.8976 & 104 \\
\hline 13 & Process Development and Test & 2.697 & 0.8506 & 99 \\
\hline 13 & Customer Focus & 2.697 & 1.0542 & 99 \\
\hline 15 & Joining, Welding \& Assembly & 2.676 & 0.8492 & 105 \\
\hline 16 & Design for X (Mfg/Assy/Maint.,etc.) & 2.653 & 0.9320 & 101 \\
\hline 17 & Process Documentation & 2.650 & 0.9143 & 100 \\
\hline 18 & Tool and Equipment Selection & 2.647 & 0.8634 & 102 \\
\hline 19 & Statistical Control Methods & 2.646 & 0.8609 & 99 \\
\hline 20 & CNC/PLC/Computer Control & 2.643 & 0.8881 & 98 \\
\hline 21 & Hot and Cold Forming & 2.635 & 0.8251 & 104 \\
\hline 22 & Human Factors, Ergonomics, Safety & 2.634 & 0.8686 & 101 \\
\hline & & & & \\
\hline
\end{tabular}




\begin{tabular}{|c|c|c|c|c|}
\hline 23 & Mechanics of Materials & 2.619 & 0.9940 & 105 \\
\hline 24 & Work Instructions & 2.604 & 0.8612 & 101 \\
\hline 25 & Inspection/Test/Validation & 2.592 & 0.7843 & 98 \\
\hline 26 & Casting and Molding & 2.585 & 0.8604 & 106 \\
\hline 27 & Composites & 2.579 & 0.9011 & 107 \\
\hline 28 & Quality Systems \& Standards (incl. ISO/TS) & 2.571 & 0.8495 & 98 \\
\hline 29 & Rapid Prototyping/Additive Manuf/3D Printing & 2.566 & 0.9811 & 99 \\
\hline 30 & Hand Tool Use \& Machine Operating & 2.552 & 0.9092 & 105 \\
\hline 31 & Process Planning \& Development & 2.550 & 0.9574 & 100 \\
\hline 32 & Metrology & 2.525 & 0.8846 & 99 \\
\hline 33 & Product Manufacturing System Design & 2.525 & 0.8555 & 101 \\
\hline 34 & Concurrent Engineering & 2.520 & 0.9154 & 100 \\
\hline 35 & Production System Build and Test & 2.500 & 0.8983 & 102 \\
\hline 35 & Control Systems (Mech/Elec/Fluid) & 2.500 & 0.8706 & 96 \\
\hline 37 & Heat Treatment & 2.495 & 0.9315 & 105 \\
\hline 38 & Finishing & 2.490 & 0.8125 & 104 \\
\hline 39 & Business \& Engineering Ethics & 2.474 & 1.0089 & 95 \\
\hline 40 & Electrical/Electronics Manufacturing & 2.472 & 0.8642 & 106 \\
\hline 41 & Capability Analysis & 2.439 & 0.9423 & 98 \\
\hline 42 & Electrical Circuits/Electronics & 2.425 & 0.9557 & 106 \\
\hline 43 & Simulation for Engineering Design & 2.384 & 0.9970 & 99 \\
\hline 44 & Capacity Planning & 2.380 & 0.9404 & 100 \\
\hline 45 & Factor Analysis (DOE/Correlation) & 2.378 & 0.8557 & 98 \\
\hline 46 & Work Holding Tool Design & 2.373 & 0.9326 & 102 \\
\hline 47 & Statics and Dynamics & 2.346 & 1.1215 & 104 \\
\hline 48 & Human Behavior/ Leadership & 2.344 & 0.9383 & 93 \\
\hline 49 & Design Management & 2.333 & 0.9047 & 102 \\
\hline 49 & Automated Systems (Hard/Flexible) & 2.333 & 0.8165 & 96 \\
\hline 51 & Reliability Analysis & 2.323 & 0.8551 & 99 \\
\hline 52 & Simulation for Process Analysis & 2.313 & 0.8648 & 99 \\
\hline 53 & Computer Systems and Networks & 2.313 & 0.9326 & 96 \\
\hline 54 & Facility Planning/Plant Layout & 2.284 & 1.0184 & 102 \\
\hline 55 & Material Handling \& Packaging & 2.283 & 0.8592 & 106 \\
\hline 56 & Process Research \& Development & 2.273 & 0.9127 & 99 \\
\hline 57 & Die/Mold Design & 2.262 & 0.8397 & 103 \\
\hline 58 & Power Systems (Mech/Elec/Fluid) & 2.258 & 0.8451 & 97 \\
\hline 59 & Maintenance Systems & 2.257 & 0.8325 & 101 \\
\hline 60 & Machine Design & 2.255 & 0.9301 & 102 \\
\hline 61 & Customer and Field Service & 2.224 & 0.9689 & 98 \\
\hline 62 & Environ. Protection/Green/Waste Mgt/Sustainability/ISO14000 & 2.218 & 0.9445 & 101 \\
\hline 63 & Education and Training & 2.211 & 1.0095 & 95 \\
\hline 64 & Standards, Laws, Regulations & 2.202 & 0.9901 & 94 \\
\hline 65 & Equipment Cycle-time Optimization & 2.179 & 1.0516 & 95 \\
\hline 65 & Time-study / Work Measurement & 2.179 & 0.9451 & 95 \\
\hline 67 & Ceramics & 2.143 & 0.9449 & 105 \\
\hline
\end{tabular}




\begin{tabular}{|l|l|l|l|l|}
\hline 68 & Theory of Constraints concepts & 2.141 & 1.0852 & 92 \\
\hline 69 & Cutting Tool Design & 2.137 & 0.8564 & 102 \\
\hline 69 & Gage Design & 2.137 & 0.7965 & 102 \\
\hline 71 & Product Liability & 2.109 & 0.9263 & 101 \\
\hline 72 & Personnel Management & 2.108 & 0.9144 & 93 \\
\hline 73 & Information Technology & 2.104 & 0.8763 & 96 \\
\hline 74 & Strategic Planning & 2.097 & 1.0007 & 93 \\
\hline 75 & Fluid Mechanics & 2.088 & 0.9760 & 102 \\
\hline 76 & Bulk and Continuous Flow & 2.087 & 1.0395 & 103 \\
\hline 77 & Supply Chain Management \& Logistics & 2.064 & 1.0555 & 94 \\
\hline 77 & Social Responsibility & 2.064 & 0.9816 & 94 \\
\hline 79 & Fluids & 2.058 & 0.8837 & 103 \\
\hline 80 & Marketing/Sales/Lifecycle Analysis & 2.029 & 0.9441 & 103 \\
\hline 81 & Organizational Design \& Management & 2.021 & 0.9614 & 94 \\
\hline 82 & Global Competition & 2.011 & 1.0106 & 94 \\
\hline 83 & Thermodynamics/Heat Transfer & 2.000 & 0.9600 & 103 \\
\hline 84 & Intellectual Property Protection & 1.931 & 1.0701 & 101 \\
\hline 85 & Database Systems (MIS, etc.) & 1.928 & 0.8196 & 97 \\
\hline 86 & Enterprise Wide Systems Integration & 1.927 & 0.9760 & 96 \\
\hline 87 & Nanotechnology & 1.903 & 1.0893 & 103 \\
\hline 88 & Accounting/Finance/Economics & 1.883 & 0.9023 & 94 \\
\hline 89 & Packaging Systems & 1.865 & 0.8159 & 96 \\
\hline 90 & Operation Research/ Forecasting & 1.862 & 0.8872 & 94 \\
\hline 91 & Natural Materials & 1.837 & 0.9564 & 104 \\
\hline 92 & Infrastructure/Plant Location & 1.822 & 0.9838 & 101 \\
\hline 93 & Labor Relations & 1.789 & 0.9664 & 95 \\
\hline 94 & Thermodynamics/Heat Transfer & 1.782 & 0.9445 & 101 \\
\hline 95 & Glasses & 1.767 & 0.8879 & 103 \\
\hline 96 & Hybrids & 1.712 & 1.0017 & 104 \\
\hline 97 & Foams & 1.549 & 0.8160 & 102 \\
\hline 98 & Auto ID Technologies/ Radio Frequency ID & 1.532 & 0.8257 & 94 \\
\hline 99 & Can speak any foreign language & 1.463 & 0.9655 & 95 \\
\hline & & & & \\
\hline
\end{tabular}


Appendix B. Number and Distribution of Respondents, with Demographics

- 129 total responses, 107 were considered valid, useful, and were used in analysis.

- Of the 107 responses that were used in the analysis:

o Many had partial answers or incomplete surveys, even on demographic categories. The absence of an answer was NOT considered the same as a zero.

o Multiple responses were accepted and even encouraged for demographic type information such as professional position, degree program and industry area.

o Nine did not cite a position, but are included in the respondent analysis figures. There was no special category of those who did not indicate a professional position.

o Seven did not indicate a degree program; however, this was added as a degree program option- - No program Specified."

o Nineteen of the 107 responses did not indicate an industry area of experience, while others selected multiple responses as was encouraged. Most selected one or two of the 20 categories,

o The vast majority (91 of 107) answered most all of the 99 topic questions.

- Figures, calculations and analysis include only the 107 responses considered valid.

- Respondents locations of those providing info. ( 25 states, one from Canada; 36 did not provide location info):

\begin{tabular}{|l|l|l|l|l|}
\hline AL & AR & AZ & CA & CO \\
\hline CT & GA & IL & IN & KS \\
\hline KY & MA & MI & MO & NC \\
\hline NH & NY & OH & OR & PA \\
\hline TN & TX & UT & WA & WV \\
\hline
\end{tabular}

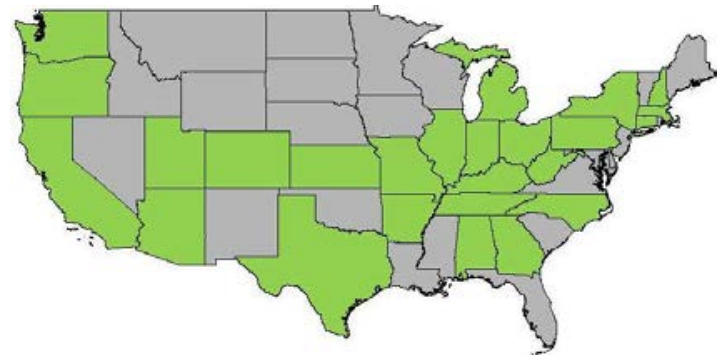

General summary of data used for program evaluation unat inciuces tne uupıcates unat were allowed. Some responses indicated multiple programs and/or more than one position and have duplicated records.

- 111 industry (Manufacturing Management or Manufacturing Engineer)

- 82 educator (Manufacturing Educator or Academic Administration)

- 113 Engineering Technology (ASET \& BSET)

- 108 Industrial Technology (ASIT, BSIT-Mgt Track, BSIT- Tech Track)

- 35 Engineering (BS-Engr.) 


\section{Appendix C. Comments by Survey Respondents to Indicated Questions}

- How prepared should graduates be in these Engineering Sciences?

o Nanotechnology is Very Important, as is Composites, but not in a day to day league with metal yet and should not be over emphasized. as such.

o (Add) material forms like powders, granules, etc.

- How prepared should graduates be in these Manufacturing Processes?

o Add additive technologies - critical

o (Add) injection mold making, Tool making, tool and die design for manufacturing options understanding during the design phase area needed.

o (Add) Direct-digital manufacturing (rapid prototyping)

- How prepared should graduates be in these Product Design topics?

o All core disciplines for the Mechanical Engineer at a company. Engineering Grads and interns have been very weak in CAD drawings preparation, one of the only skills that can be used on Day 1 . Need more emphasis on this. The Engineering Drawing controls 100\% of the engineering project, worldwide, any language.

o I believe a level of safety training needs to be in here. Not just a glanced over version

o (Add) Lean Mfg

- How prepared should graduates be in these Process Design topics?

o (Add) Print Reading and Creating.

- How prepared should graduates be in these Equipment/Tool Design topics?

o Depends on type of engineer

- How prepared should graduates be in these Production System Design topics?

o Safety is first priority.

- General comments

o (T)hese are all dependent upon the individual's job responsibilities. 